International Journal of Advanced Technology in Mechanical, Mechatronics and Materials
(IJATEC)
Vol. 01, No. 3 (2020) 108-117
Institute for Research on Innovation and Industrial System (IRIS)

\title{
Occupational Safety and Health (OSH) Practices and Its Influenced Factor - Review OSH in Malaysia
}

\author{
Dafit Feriyanto*a, S.S. Abdulmalik ${ }^{b}$, Supaat Zakariac \\ a Department of Mechanical Engineering, Faculty of Engineering, Universitas Mercu Buana, Jakarta, Indonesia \\ ${ }^{b}$ Department of Mechanical Engineering, Faculty of Engineering and Technology, Nigerian Army University, \\ Borno State, Nigeria \\ cDepartment of Mechanical Engineering, Politeknik Ungku Omar, Ipoh, Perak, Malaysia
}

\begin{abstract}
High occupational accident in Malaysia as reported by Department of Occupational Safety and Health (DOSH) Malaysia shows the urgently applied a occupational safety and health (OSH) practices in workplaces. Its review was conducted through the literature review from the related journal and agency report in order to observe the latest information in terms of OSH in Malaysia. This study purposed to review the OSH practices in Malaysia and its influence factor. The factor of that influence to accident cases, good OSH practice and OSH system and framework as well as agencies that has authority with OSH was briefly explained. Factor that influence to the accident was consists of various factors such as stress and fatigue, unsafe act, machinery/tools, design of workplace and training procedure. Influenced factors to achieve good OSH practices were consists of training, safe work procedure, consultation, reporting safety, management commitment and injury management. Several OSH agencies that has been developed in Malaysia such as NIOS, NCOSH, DOSH and SOCSO as program in the institution. Institution contribute an important factor due to in institution teach a fundamental of OSH that may applied in the workplaces.
\end{abstract}

Keywords: occupational safety and health (OSH); occupational accident; OSH practices; OSH agencies

DOI: $\underline{10.37869 / \text { ijatec.v1i3.36 }}$

Received 27 November 2020; Accepted 14 December 2020; Available online 31 December 2020

(C) The Authors. Published by IRIS. This is an open access article under the CC BY-NC-SA license c) (1) (2)

\section{Introduction}

Providing good safety and health practices is very important to the community and employees [1]. It caused by there are many accident cases in workplace was reported by Department of Occupational Safety and Health (DOSH) Malaysia that divided into two which is by sector and by state. In by sector shown in Figure 1 that there are 3,246 accident cases in Malaysia from January to October 2017 where the highest number of accidents shown by Perak state for 465 cases, followed by Kedah for 327 cases, Johor 324 cases and the smallest number of accident was shown by WP Labuan for 5 cases. Moreover, accident cases also divided by sector as shown in Figure 2 that the highest accident cases was located at manufacturing sector for 1,691 cases from the total 3,246 accident cases and followed by other sector such as Manufacturing, Mining and Quarrying, Construction, agriculture, forestry, logging and fishing, utility, transport, storage and communication, wholesale and retail trade, hotel and restaurant, financial, insurance, real estate and business service and public service and statutory bodies [2][3][4].

Most of the accidents was caused within employees due to lack of awareness. Meanwhile, when a proper precaution is taken, strict rules, laws and regulation are made, provide regular employee awareness programs, the accident cases in the workplace could be controlled [1][5][6]. 


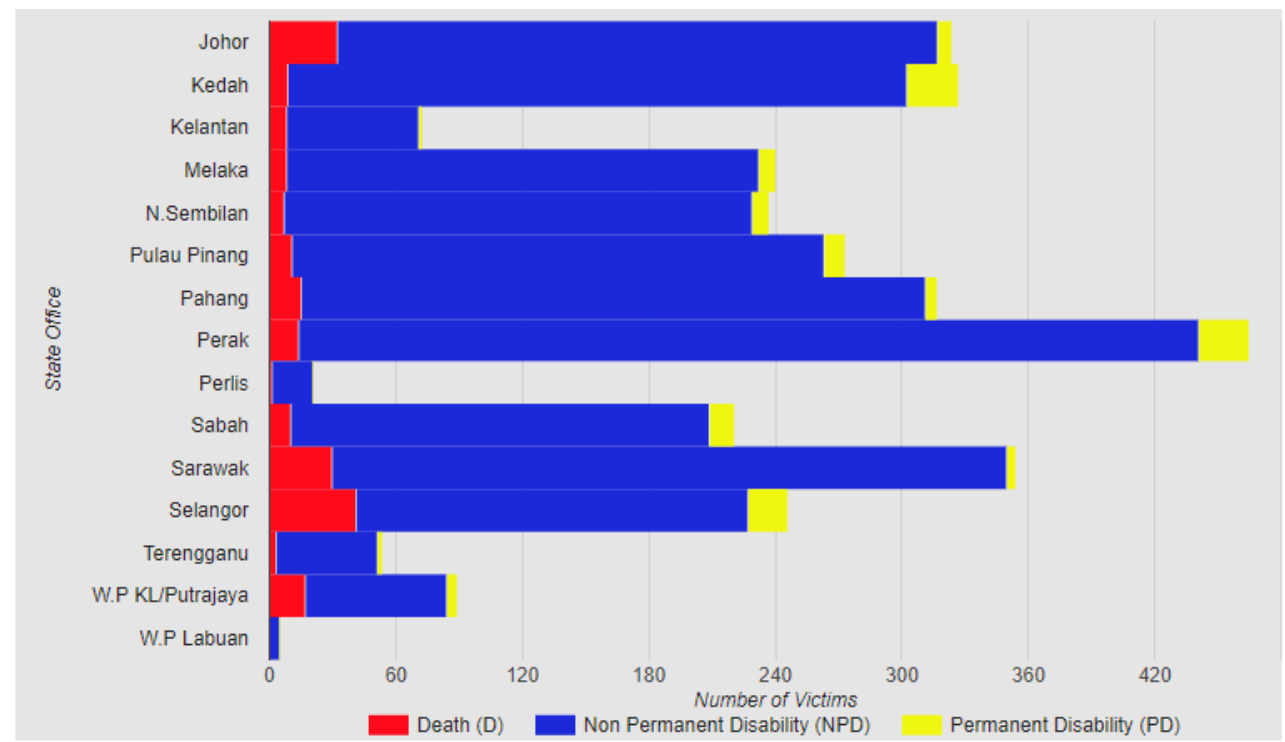

Figure 1. Occupational accident by states from January to October 2017 [3]

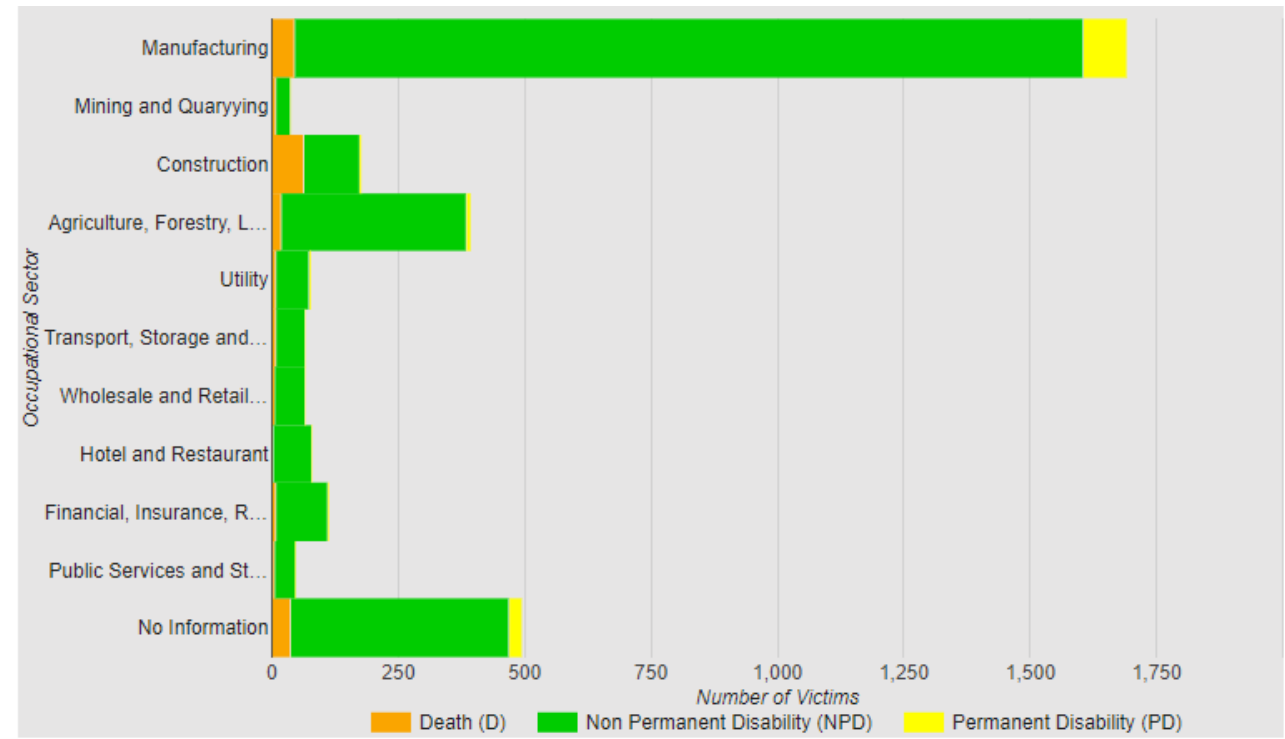

Figure 2. Occupational accident by sector from January to October 2017 [4]

\section{Factor That Influences on the Occupational Accident}

There are several factors that influence on the increasing or decreasing occupational accident in Malaysia such as stress and fatigue, unsafe act, machinery/tools, design of workplace and training procedures.

\subsection{Stress and fatigue}

These pressures or demands at work include working long hours, workload demands, and supervisory pressures. In another perspective, stress is a form of body reaction towards any problem and pressure resulted to an imbalance between our inner resources and skills on one hand, and pressures we encounter, and support received to deal with these [7].

\subsection{Unsafe act}

Human errors that could potentially cause an accident are called unsafe acts may be defined to be a human action that departs from hazard control or job procedures to which the person has been trained or otherwise informed, which causes unnecessary exposure of a person to hazards [5][8][9].

\subsection{Machineries/tools}


Accident claims involving defective or dangerous machinery are all too common in the UK. Recently, the Health and Safety Executive made a point of addressing the need for effective risk assessments in the manufacturing industry. Mechanical handling removes most of the hazards of man-handling but introduces new dangers. Injury to personnel is less frequent but tends to be more severe [1][5].

\subsection{Design of workplace}

Older buildings may contain asbestos, which will affect all occupants. Electrical wires or faulty wiring may shock office workers, literally. The majority of major injuries occur to non-drivers the poor design and layout of workplaces must be seen as a causal factor [7].

\subsection{Training procedures}

There is evidence to indicate that many workplace transport accidents are associated with poor training. Adequate training would have prevented the injuries sustained in lift truck incidents [1].

\section{Influenced factor of good OSH practices}

Good OSH practices highly contribute to the decrement occupational accident. It consists of several factors such as training, safe work procedures, consultation, reporting safety, management commitment and injury management.

\subsection{Safety and health practices}

According to Chee et al. [10], firms are attention on occupational safety performance and it has greater potential for influencing the productivity of that organization. However, the greater challenge for employees is to meet occupancy load standards for the purpose of establishing and maintaining a safe working and learning environment in their workplace. Moreover, safety awareness concerns the need for conducting research that links occupational safety performance and productivity.

\subsection{Training}

Training will encourage employees to become productive and increase safer work environment. In addition, Chee et al. [10] suggest the occupational accidents and injuries will increase because of the ineffectiveness of safety training. Kasim et al. [11] stated supervision is a combination of the elements such as goals, functions, tasks, roles, strategies, process elements, personalities, beginnings, middles, and endings to make a process. It is a very complex process.

\subsection{Safe Work Procedures}

Safe work procedures are an important to employees to ensure their organization in a safer work environment with implementing safety and health practices to manage injuries and accidents in the workplace. In manufacturing industry, employers should implement and complied with all the guidance and procedures on safety and health at the workplace to minimize the number of accidents. Manu et al. [9] stated that favorable and unfavorable outcomes are the determination of employee's behavior to know their future behavior. According to Kuok et al. [12], they said workplace injuries can be decreased or avoided and all the employees can manage the human error properly if proper procedure's safety implementing for employees. Thus, employees should work towards demonstrating a positive safety attitude, a sound knowledge of safety, and maintain safe working conditions.

\subsection{Consultation}

In order to encourage consultation and communication, it is important not to blame employees when accidents occur. As managers have gained experience with the techniques used to improve quality, they have learned the importance of improving the process of production. Referred to Chee et al. [10], consultation is the relationship between management and employees in order to exchange views and engaging in dialogue. Besides that, it is variable from a collecting bargaining between employer and employees.

\subsection{Reporting Safety}


In these practices, Chee et al. [10], stated an internal reporting as a person to handle all those reporting from employees in that organization. It is important for lecturers to encouraging internal reporting gives upper management more control to the problem and creates opportunities for their organizations to deal with their own misconduct in an effective and responsible manner. Normally, many lecturers would disclose information externally if they have no confidence in management actions or believe their concerns will not be considered properly.

\subsection{Management Commitment}

Management commitment is about the employees committed to their employer in safety and health issues. The top management plays an important role in reducing the injuries or accidents to their workers in the workplace while employees also are crucial to give commitment to support the practices. Chee et al. [10], management commitment defined as the management always show a positive and supportive safety and health attitudes to their employees' perception about safety in the workplace.

\subsection{Injury management}

Safety is the state in which the risk of harm to persons or property damage is reduced and maintained at or below, an acceptable level through a continuing process of hazard identification and risk management. Injury management as referred to Ismail et al. [8] and Saifullah \& Ismail [13], stated that the determinant of injury risk is the attitudes and safety and health practices in the workplace. The injury management can improve the safety and health practices in the workplace and employee also less suffering towards injuries and accidents. However, the injury management can reduce costs for an organization.

\section{Safety and health system and framework}

In terms of safety and health system that developed by Ramli et al. [5], that the elements of the work system include person, tasks, technology and tools, environment, and organization as illustrated in Figure 3. The interaction between each work system elements can affect the work performance or outcomes. According to Systems Engineering Initiative for Patient Safety (SEIPS) model, individuals use technology and tools to perform tasks in an environment under certain organizational conditions. SEIPS model can be used to analyse or categorize the contributing factors of patient safety events, and anticipate potential safety consequences of the introduction of health IT.

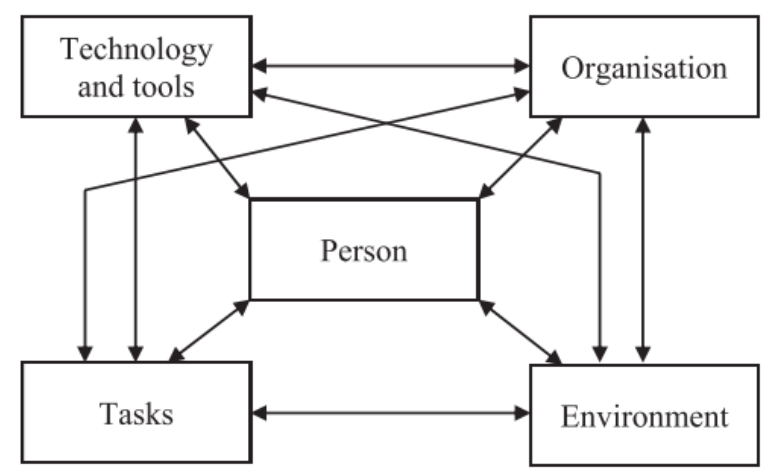

Figure 3. Work system components adapted from SEIPS model [5]

The conceptual framework that has been proposed to create a good OSH practice of safe work environment illustrated in Figure 4. It grouped into 2 which is independent variable which consist of training and supervision, safe work procedure, consultation, reporting safety and management commitment as well as dependent variable which is injury management [1]. 


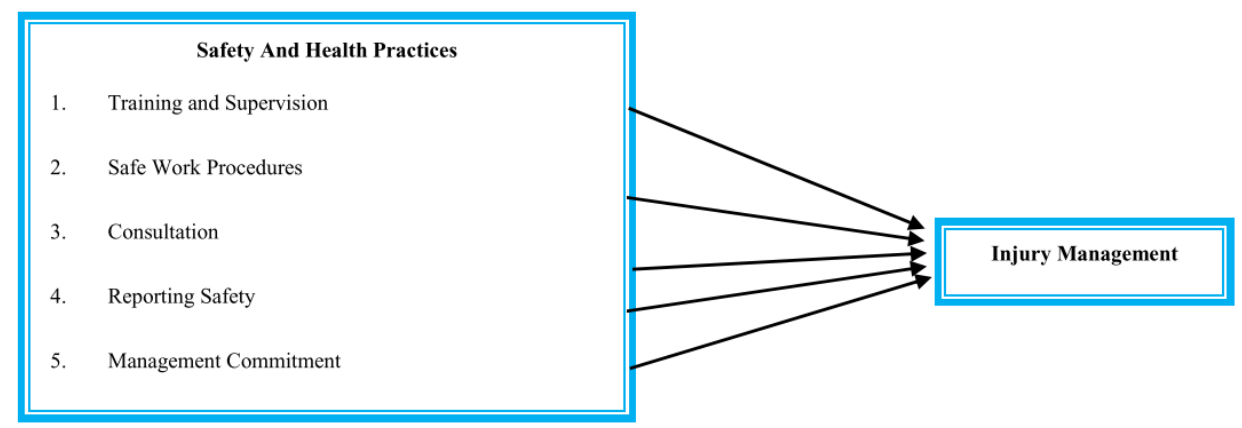

Figure 4. Conceptual framework of OSH practice

\section{The five factors of initial framework development}

There are 5 factors that effect to the cooperative safety management such as organization, financial, institution, legislation, and technology.

\subsection{Organization}

The cooperative relationship is more likely to be formed when each of the participants belief in trust and openness. These two attributes are sine qua non for the establishment of the cooperative network. The trust is a critical factor that hinders and discourages cooperation [14], and it plays a decisive role in cooperation between organizations [15]. The cooperative relationship is also characterized by openness, where firms are in propensity to exchange information, examine the existing differences and find effective solutions that are mutually accepted. However, cooperative relationship may easily be unraveled without proper planning and transparent agreement. Indeed, it is imperative to ensure the sustain- ability of cooperative relationship among all participants through an in-depth understanding on the notion of cooperation advantages. The decisive management team may think that cooperative network for safety is pseudo-intelligence and of triviality.

\subsection{Financial}

The main drawback to cooperative agreement is the cost factor. The financial support mechanism may motivate firms to work cooperatively or implement the programs consensually. This is because some of the initiatives require huge investment, especially in R\&D and implementation of innovated technologies. The financial constraint is a critical factor and at the same time is unavoidable. However, the cooperative behavior through policy intervention is difficult to develop from scratch and indeed financial support is needed at each phase of evolution. In short, the success of symbiotic agreement for cluster safety management, sometimes, requires extensive research and strategy. Thus, financial matter should be a part of the factor that ought to be embedded into the planning of the cooperative network [5].

\subsection{Institution}

In Malaysia, there are various institutions involved in safety and health matters. Among these institutions are, inter alia, the Department of Occupational Safety and Health (JKKP), National Institution of Occupational Safety and Health (NIOSH, the training provider), Social Security Organization (PERKESO), National Council of Occupational Safety and Health, and National Security Council (MKN). The cooperative approach towards the enhancement of industrial cluster's safety is pre- ceded by institutional care. There should be a structured and independent body to monitor, strategize, and coordinate both planning and implementation, and notwithstanding the hidden interest of the participants. However, these non-superfluous institutions are important to avoid jurisdictional conflict, especially when it comes to implementation and enforcement. The role of multi-institutions in working cooperatively with the industry as well as with themselves will improve the movement towards the establishment of cooperative networking. The industrial safety-related institutions should be given a privilege to intervene cooperatively in the planning and implementation of this initiative. The government agencies, in particular, ought to be involved 
proactively since they have convening and enforcement power. Moreover, industries would react to a problem identified in a public discourse [6][16][17].

\subsection{Legislations}

The cooperative network may be against the existing legislations, especially when dealing with firm's confidentiality. Thus, either amendments or bills should be discussed and tabled in the parliament. Additionally, besides a voluntarily- based safety and health system, the legal and state's input will also be influential to enhance safety performance [8]. However, this is not a straightforward move and the authorities have to make a detour due to its complexity. The laws and policies are a final arbiter to either allow or stop the process of this interaction. However, industrial operators should not consider the legislations as an onerous administrative duty but as a chance to demonstrate their responsible attitudes [13]. They added that dialogue and cooperation among industrial community, competent authorities and public should be given a priority rather than confrontation. A legal framework ought to be proposed for ameliorating inter-company relationship. In Malaysia, the legislations relating to safety and health issues are the Occupational Safety and Health Act (1994) and Factory and Machinery Act (1967), to name a few. As for Factory and Machinery Act, this act only covers the occupational safety and health in the manufacturing, mining, quarrying and construction industries.

\subsection{Technology}

Technology development is inexorably continual. By adopting the modern and advanced technology, the issues of safety that is lingering among industrial communities can be minimized and confronted. Modern safety management method and advanced science and technology may offer effective ways to reduce mistakes [18]. However, the use of advanced technology may require rigorous risk assessment that involve technical risks associated with system's components, its operators, environment, physical hazards and the regulations [19]. This is imperative because even though all the system's components have not failed and operated reliably but it seem that system design errors has become the cause of major accidents, which shows an increment in trend [20]. If the systems do not have an ability to detect unwanted disturbances as well as unable to manipulate operating variables, these may initiate incidents [12]. Thus, the system modelling in high-risk industries requires a new approach following the development of technological innovation [21].

Table 1. The set of question that addressing to the current condition of industrial safety management in Malaysia

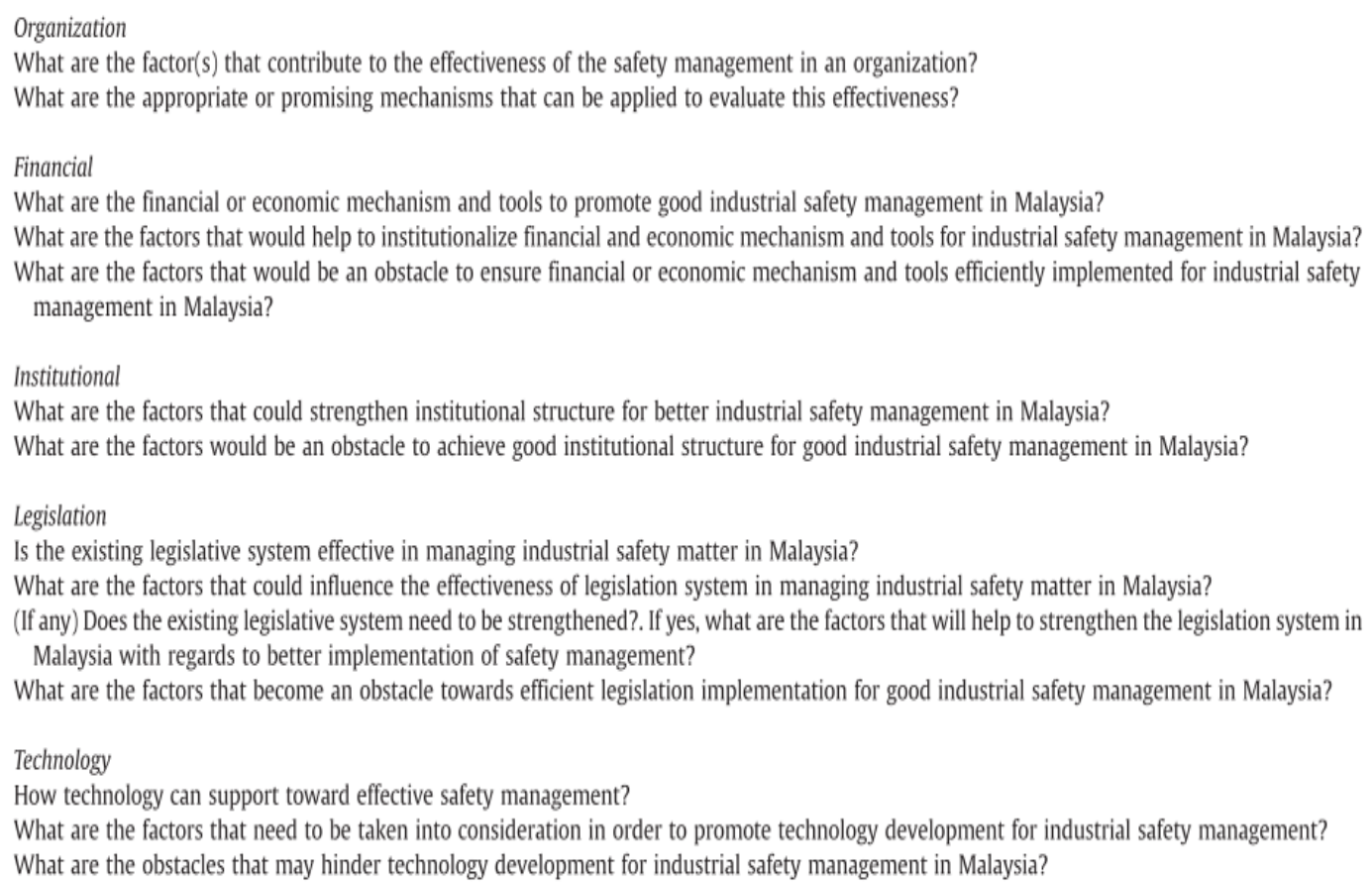




\section{Agencies for success $\mathrm{OSH}$ practices}

In Malaysia, there are several government agencies that related to OSH practices such as National Institute for Occupational Safety and Health (NIOSH), National Council for Occupational Safety and Health (NCOSH), Department of Occupational Safety and Health (DOSH), The Social Security Organization (SOCSO) and institution centre which called by OSH-WE.

\subsection{The National Institute for Occupational Safety and Health (NIOSH)}

Federal agency responsible for conducting research and making recommendations for the prevention of work-related injury and illness. Part of the Centers for Disease Control and Prevention (CDC) in the Department of Health and Human Services. NIOSH has several roles as detail [22]:

1) Generate new knowledge in the field of occupational safety and health.

2) Transfer that knowledge into practice for the betterment of workers.

3) An agency established to help assure safe and healthful working conditions for working men and women (by providing research, information, education, and training in the field of occupational safety and health.)

4) Prevent work-related illness, injury, disability, and death by gathering information, conducting scientific research, and translating the knowledge gained into products and services for improving safety and health.

\subsection{National Council for Occupational Safety and Health (NCOSH)}

NCOSH under the Ministry of Human Resources is a supreme body responsible for determining the direction and policy of the State in relation to occupational safety and health in Malaysia. It was established in 1995 in accordance with Section 8 of the Occupational Health and Safety Act 1994 (Act 514). The main objective of NCOSH establishment is a continuous effort by the government to ensure the safety, health and welfare of employees in the workplace is secure. NCOSH has several function as detail [23]:

1) Changes it considers desirable to occupational safety and health legislation;

2) The improvement of the administration and enforcement of occupational safety and health legislation;

3) The fostering of a co-operative consultative relationship between management and labour on the safety, health and welfare of persons at work;

4) The special problems with respect to occupational safety, health and welfare of women, handicapped persons and other groups in the community;

5) The establishment of adequate methods of control of industrial chemicals at a place of work;

6) The statistical analysis of occupationally related deaths and injuries;

7) The provision of health care facilities at a place of work;

8) The fostering of the development and adoption by law of industry codes of practice related to occupational safety, health and welfare; and

9) The development of rehabilitation plans and facilities to assist persons injured at a place of work.

\subsection{Department of Occupational Safety and Health (DOSH) Malaysia}

Main purpose of this agency was to provide a safe and health work environment for all its employees and to protect other who may be affected by its activities and known as the Jabatan Keselamatan dan Kesihatan Pekerjaan. There are several functions of DOSH such as [2]:

1) To study and review the policies and legislations of occupational safety and health.

2) To enforce the following legislations:

a. Occupational Safety and Health Act 1994 and its regulations.

b. Factories and Machinery Act 1967 and its regulations.

c. Part of Petroleum Act 1984 (Safety Measures) and its regulations.

3) To conduct research and technical analysis on issues related to occupational safety and health at the workplace.

4) To carry out promotional and publicity programs to employers, workers and the general public to foster and increase the awareness of occupational safety and health. 
5) To become a secretariat for the National Council regarding occupational safety and health.

In this Department also has several roles such as:

1) To prepare and preserve a workplace with a safe and health working system.

2) To ensure all staff are provided with the relevant information, training and supervision regarding methods to carry out their duties in a safe manner and without causing any risk to health.

3) To investigate all accidents, diseases, poisonous and/or dangerous occurrences, and to have action to ensure that these occurrences will not be repeated.

4) To comply with all requirements of legislation related to safety and health as stated in the Occupation Safety and Health Act 1994, as well as regulation and codes of practice which have been approved.

5) To provide basic welfare facilities to all workers

6) To revise and improve on this policy whenever necessary.

\subsection{The Social Security Organization (SOCSO)}

SOCSO is an organization set up to administer, enforce and implement the Employees' Social Security Act, 1969 and the Employees Social Security (General) Regulation 1971. SOCSO was Commonly known as Perkeso or Pertubuhan Keselamatan Sosial in Malay term. SOCSO have employees with a monthly income of RM3000 and below, along with their employees are required to make contributions. SOCSO also have several roles as detail [24]:

1) Provide social security protection by social insurance including medical, cash benefits, provision of artificial aids and rehabilitation to employees to reduce the sufferings.

2) Provides social security protection by social insurance including medical and cash benefits.

3) Provision of artificial aids and rehabilitation to employees to reduce the suffering and provide financial guarantees and protection to the family.

\section{Conclusion}

Occupational safety and health practices in workplace was very important in order to achieve safe work environment. Besides that, it purposed to reduce the occupational accident either death, nonpermanent disability or permanent disability. Several factor that influence to occupational accident (stress and fatigue, unsafe act, machinery/tools, design of workplace and training procedure), factor that influenced to achieve good OSH practices (training, safe work procedure, consultation, reporting safety, management commitment and injury management), OSH system and framework has been reviewed. There are several OSH agencies that has been developed in Malaysia such as NIOS, NCOSH, DOSH and SOCSO as program in the institution. Even DOSH has been developing the Occupational Safety and Health Master Plan for Malaysia, but safety and health practices still need to be improved in order to eliminate the occupational accident in Malaysia.

\section{Acknowledgment}

The authors would like to thank the Universitas Mercu Buana for funding support

\section{References}

[1] Hanim, F., Mohamed, B., Zulkifle, Z. B., Binti, S. Z., \& Kadir, A. (2016). Safety and Health Practices and Injury Management In Manufacturing Industry. Procedia Economics and Finance, 35(October 2015), 705-712. http://doi.org/10.1016/S2212-5671(16)00088-5

[2] Department of Occupational Safety and Health (DOSH). (2018). Retrieved by 23 March 2018 in: http://www.dosh.gov.my/index.php/en/about-us/dosh-policy

[3] Department of Occupational Safety and Health (DOSH). (2018a). Retrieved by 23 March 2018 in: http://www.dosh.gov.my/index.php/en/occupational-accident-statistics/by-state

[4] Department of Occupational Safety and Health (DOSH). (2018b). Retrieved by 23 March 2018 in: http://www.dosh.gov.my/index.php/en/occupational-accident-statistics/by-sector 
[5] Ramli, A., Mokhtar, M., \& Abdul, B. (2014). International Journal of Disaster Risk Reduction The development of an initial framework for multi-firm industrial safety management based on cooperative relationship: A Malaysia case study. International Journal of Disaster Risk Reduction, 10, 349-361. http://doi.org/10.1016/j.ijdrr.2014.10.002

[6] Subramanian, G. C., Arip, M., \& Subramaniam, T. S. S. (2017). Knowledge and Risk Perceptions of Occupational Infections Among Health-care Workers in Malaysia. Safety and Health at Work, 8(3), 246-249. http://doi.org/10.1016/j.shaw.2016.12.007

[7] Salahuddin, L., \& Ismail, Z. (2015). International Journal of Medical Informatics Classification of antecedents towards safety use of health information technology: A systematic review. International Journal of Medical Informatics, 84(11), 877-891. http://doi.org/10.1016/i.ijmedinf.2015.07.004

[8] Ismail, F., Ahmad, N., Afida, N., \& Janipha, I. (2012). Assessing the Behavioural Factors' of Safety Culture for the Malaysian Construction Companies, 36(June 2011), 573-582. http://doi.org/10.1016/j.sbspro.2012.03.063

[9] Manu, P., Mahamadu, A., Phung, V. M., Nguyen, T. T., Ath, C., Ying, A., ... Kit, S. C. (2017). Health and safety management practices of contractors in South East Asia: A multi country study of Cambodia, Vietnam, and Malaysia. Safety Science. http://doi.org/10.1016/j.ssci.2017.07.007

[10] Chee, H., Ramayah, T., \& Subramaniam, C. (2018). The relationship between critical success factors, internal control and safety performance in the Malaysian manufacturing sector, 104(February), 179-188. http://doi.org/10.1016/j.ssci.2018.01.002

[11] Kasim, H., Rosmani, C., Hassan, C., Diana, M., \& Davazdah, S. (2018). Determination of factors a ff ecting safety practices in Malaysian radiation facilities. Safety Science, 104(November 2017), 7080. http://doi.org/10.1016/j.ssci.2017.12.031

[12] Kuok, D., Tang, H., Leiliabadi, F., Udoncy, E., \& Zawiah, S. (2017). Factors affecting safety of processes in the Malaysian oil and gas industry. Safety Science, 92, 44-52. http://doi.org/10.1016/j.ssci.2016.09.017

[13] Saifullah, N. M., \& Ismail, F. (2012). Integration of Occupational Safety and Health during Pre$\begin{array}{llll}\text { construction Stage in } & \text { 2011), 603-610. }\end{array}$ http://doi.org/10.1016/j.sbspro.2012.02.127

[14] Safizal, M., Hj, Y., Osman, A., \& Nizam, S. (2016). Safety Culture Behaviour in Electronics Manufacturing Sector (EMS) in Malaysia: The Case of Flextronics. Procedia Economics and Finance, 35(October 2015), 454-461. http://doi.org/10.1016/S2212-5671(16)00056-3

[15] Hafiza, N., Razak, A., Praveena, S. M., Hashim, Z., \& Zaharin, A. (2015). Drinking water studies: A review on heavy metal, application of biomarker and health risk assessment (a special focus in Malaysia). Journal of Epidemiology and Global Health, 5(4), 297-310. http://doi.org/10.1016/j.jegh.2015.04.003

[16] Mansor, M., \& Harun, N. Z. (2014). Health Issues and Awareness, and the Significant of Green Space for Health Promotion in Malaysia. Procedia - Social and Behavioral Sciences, 153, 209-220. http://doi.org/10.1016/j.sbspro.2014.10.055

[17] Takim, R., Zulkifli, M. H., \& Nawawi, A. H. (2016). Integration of Automated Safety Rule Checking (ASRC) System for Safety Planning BIM-Based Projects in Malaysia. Procedia - Social and Behavioral Sciences, 222, 103-110. http://doi.org/10.1016/i.sbspro.2016.05.195

[18] Khairlida, N., Khair, M., Lee, K. E., Mokhtar, M., \& Goh, C. T. (2018). Integrating responsible care into quality, environmental, health and safety management system: A strategy for Malaysian chemical industries. Journal of Chemical Health \& Safety. http://doi.org/10.1016/i.jchas.2018.02.003

[19] Al-anbari, S., Khalina, A., Alnuaimi, A., Normariah, A., \& Yahya, A. (2015). Risk assessment of safety and health (RASH) for. Process Safety and Environmental Protection, 94, 149-158. http://doi.org/10.1016/i.psep.2015.01.009

[20] Fernando, Y., Ng, H. H., \& Yusoff, Y. (2014). Activities, motives and external factors in fl uencing food safety management system adoption in Malaysia. Food Control, 41, 69-75. http://doi.org/10.1016/j.foodcont.2013.12.032

[21] Baba, I., Hin, K., Abdul, M., \& Azid, A. (2018). Chemosphere Consumption of water from ex-mining ponds in Klang Valley and Melaka, Malaysia: A health risk study, 195. http://doi.org/10.1016/j.chemosphere.2017.12.112

[22] National Institute for Occupational Safety and Health (NIOSH). (2018). Retrieved by 23 March 2018 in: http://www.niosh.com.my/corporate-info/niosh-policy/safety-and-health-policy 
[23] National Council for Occupational Safety and Health (NCOSH). (2018). Retrieved by 23 March 2018 in: http://www.dosh.gov.my/index.php/en/about-ncosh/latarbelakang

[24] Social Security Organization (SOCSO). (2018). Retrieved by 23 March 2018 in: https://www.perkeso.gov.my/index.php/ms/ 